\title{
The benefit of consolidation radiotherapy to initial disease bulk in patients with advanced Hodgkin's disease who achieved complete remission after standard chemotherapy
}

\author{
This article was published in the following Dove Press journal: \\ Journal of Blood Medicine \\ 20 March 2015 \\ Number of times this article has been viewed
}

\author{
Yasser Bayoumi ${ }^{1,2}$ \\ Abdulaziz Al-Homaidi ${ }^{3}$ \\ Syed Zaidi ${ }^{3}$ \\ Imran Tailor ${ }^{3}$ \\ Ibrahiem Motiabi ${ }^{3}$ \\ Nawal Alshehri ${ }^{3}$ \\ Assem Al-Ghazali ${ }^{3}$ \\ Samer Almudaibigh ${ }^{3}$ \\ 'Radiation Oncology, National Cancer \\ Institute, Cairo University, Egypt; \\ ${ }^{2}$ Radiation Oncology Department, \\ ${ }^{3}$ Department of Haematology and \\ Oncology, Comprehensive Cancer \\ Center, King Fahad Medical City, \\ Riyadh, Saudi Arabia
}

\begin{abstract}
Background/purpose: The aim of this study was to evaluate the role of consolidation radiotherapy (RT) in advanced-stage Hodgkin's disease (HD) with initial bulky sites after radiological complete remission (CR) or partial response (PR) with positron emission tomographynegative (metabolic CR) following standard chemotherapy (ABVD [Adriamycin, bleomycin, vinblastine, and dacarbazine]) six to eight cycles.
\end{abstract}

Patients and methods: Adult patients with advanced-stage HD treated at our institute during the period 2006 to 2012 were retrospectively evaluated. One hundred and ninety-two patients with initial bulky disease size $(>7 \mathrm{~cm})$ who attained radiological $\mathrm{CR} / \mathrm{PR}$ and metabolic $\mathrm{CR}$ were included in the analysis. One hundred and thirteen patients who received radiotherapy (RT) as consolidation postchemotherapy (RT group) were compared to 79 patients who did not receive RT (non-RT group). Disease-free (DFS) and overall survival (OS) rates were estimated using the Kaplan-Meier method and were compared according to treatment group by the log-rank tests at $P \leq 0.05$ significance level.

Results: The mean age of the cohort was 33 (range: 14 to 81 ) years. Eighty-four patients received involved-field radiation and 29 patients received involved-site RT. The RT group had worse prognostic factors compared to the non-RT group. Thirteen (12\%) relapses occurred in the RT group, and 19 (24\%) relapses occurred in the non-RT group. Nine patients ( $8 \%)$ in the RT group died, compared to eleven patients $(14 \%)$ in the non-RT group. Second malignancies were seen in only five patients: three patients in the RT group compared to two patients in the non-RT group. At 5 years, overall DFS was $79 \% \pm 9 \%$ and OS was $85 \% \pm 9 \%$. There was significant statistical difference between the RT group and the non-RT group regarding 5-year DFS: $86 \% \pm 7 \%$ and $74 \% \pm 9 \%$, respectively $(P \leq 0.02$ ). However, the 5 -year OS was $90 \% \pm 5 \%$ for the RT group and $83 \% \pm 8 \%$ for the non-RT group, with no statistical difference $(P \leq 0.3)$.

Conclusion: The results of our study suggest that consolidation RT in patients with advancedstage HD with initial bulky disease who had postchemotherapy radiologic CR or PR with metabolic CR improved the DFS.

Keywords: Hodgkin's disease, radiological and metabolic complete remission, involved-field radiation, involved-site radiation

\section{Background}

Radiotherapy (RT) in the management of Hodgkin's disease (HD) is often thought to be responsible for late life-threatening sequelae, including second malignancies; however, most of the new trials for HD involve RT as an integral part of the study design - even those that claim to be evaluating new chemotherapy regimens. ${ }^{1}$ Adding RT to the standard
Correspondence: Yasser Bayoumi Radiation Oncology, National Cancer Institute, Cairo, Egypt

Tel +966502785290

Email yasserbayoumi777@yahoo.com 
chemotherapy in advanced HD cases is a controversial issue, and this matter has not yet been completely resolved. Many trials have shown that RT enhances disease-free survival (DFS) even if no improvement in overall survival was shown. Further, the advent of novel RT techniques and the change of the radiation field from involved-field radiation to involved nodal-field radiation and involved-site radiation have made a big difference in terms of late sequelae. The modern RT techniques and radiation field preferences may also reduce the need for high-dose chemotherapy and autologous stem cell transplantation, leading to subsequent reductions in related toxicities and costs, by prolonging DFS.

Advanced-stage HD patients who achieved postchemotherapy partial response (PR) and received RT have been shown to have similar DFS as patients with postchemotherapy complete remission (CR); however, RT is not routinely justified after CR is achieved in advanced-stage HD. ${ }^{2}$

The main objective of the present study was to assess the treatment outcomes of consolidation RT in patients with advanced-stage HD with radiological CR or PR as well as well metabolic CR.

\section{Patients and methods}

After receiving approval from the relevant institutional review board, a retrospective review of adult patients with advanced-stage HD, who were treated at our institute during the period 2006 to 2012, was performed. To avoid selection bias, patients who received chemotherapy regimens other than ABVD (Adriamycin, bleomycin, vinblastine, and dacarbazine) were excluded. Only patients with initial bulky disease (more than $7 \mathrm{~cm}$ ) or who had positron emission tomography (PET)-negative radiological gross residuals were included in the analysis.

\section{Staging}

All patients were staged according to detailed history; physical examination; computed tomography of neck, thorax, abdomen, and pelvis; hematology (complete blood counts, erythrocyte sedimentation rate [ESR]); and liver function, hepatitis/hepatic virus markers, human immunodeficiency virus (HIV), and renal function tests. All cases of HD were diagnosed by an experienced hematopathologist. Classical HD was defined on the basis of characteristic morphology together with expression of CD30 and/or CD15. PET imaging was not used for staging routinely.

\section{Chemotherapy and remission assessment}

The chemotherapy regimen given was ABVD, which consisted of doxorubicin $25 \mathrm{mg} / \mathrm{m}^{2}$, bleomycin 10 units $/ \mathrm{m}^{2}$, vinblastine
$6 \mathrm{mg} / \mathrm{m}^{2}$, and dacarbazine $375 \mathrm{mg} / \mathrm{m}^{2}$ intravenously on days 1 and 15. Chemotherapy was recycled every 28 days. The number of cycles was six to eight, based on the assessment after three to four cycles. Early responders received only six cycles, and late responders received eight cycles.

Radiological CR was defined as the complete disappearance of clinical and radiologic \pm histologic (bone marrow) signs of HD. For all gross residuals evident after chemotherapy, a routine PET was used for biological assessment using the International Harmonization Project (IHP) guidelines for response criteria in lymphoma clinical trials for defining the PET-negative disease or metabolic CR. ${ }^{3}$

\section{RT}

The RT component encompassed initial bulky sites and gross residual disease, even if PET was negative. From 2006 to 2009 , the RT field used was involved-field radiation, encompassing the pre-chemotherapy-involved bulky nodes plus contiguous uninvolved lymph nodes. After 2009, along with involved-field radiation, involved-site radiation was used that covered the initially involved nodal disease or residual disease with $1.5 \mathrm{~cm}$ margin. The clinical target volume encompassed both the pre- and post-chemotherapy nodal volumes, and was restricted by post-chemotherapy anatomic limits. The additional margins accounted for interfraction set-up variation and physiological intrafraction and interfraction movement (eg, movement with respiration) were expanded to have planning target volume. Computed tomography simulation, three-dimensional conformal RT, and intensity-modulated RT were used if required.

RT was prescribed to a planned dose of 30-36 Gy in 15-18 fractions, according to the presence of residual mass after chemotherapy. RT was delivered in five fractions per week.

\section{Follow-up}

The follow-up included clinical examination, complete blood counts, ESR, and liver and renal function tests every 3 months in the first 2 years, every 6 months in the subsequent 3 years, and yearly after that. Radiological investigations were requested only in case of complaints or suspicious clinical examination.

\section{Statistical analysis}

The primary endpoint, DFS, was calculated from the end date of chemotherapy to the date of the first relapse. The secondary endpoint, overall survival (OS), was calculated from the first day of chemotherapy to the date of death. The SPSS statistical software package (v 17.0) was used for evaluation of the data. Survival curves were estimated using the Kaplan-Meier 
method and compared by the log-rank test, and a $P$-value of 0.05 was considered statistically significant. The chi-square test or, when appropriate, the Fisher's exact test (two-tailed), were used to compare qualitative data.

\section{Results}

One hundred and ninety-two patients were included in this analysis. All patients completed the planned chemotherapy treatment. RT was given to 113 patients (RT group) as per institutional guidelines; this group included patients with initial bulky disease or residual disease following chemotherapy. Seventy-nine patients did not receive RT (non-RT group), due to patient preference, primary physician decision, or multidisciplinary tumor board decision. The median follow-up period was 63 (range: 20 to 102) months.

\section{Patient characteristics}

Patient characteristics are shown in Table 1. At diagnosis, the mean age was 33 (range: 14 to 81 ) years; the RT group had a higher mean age (39.5 years) compared to the non-RT group (28 years). The male-to-female ratio was 3:2; however, the ratio in the RT group was $2: 1$, and in the non-RT group, $1: 1$. The Ann Arbor stage was IIB in $25 \%$ of patients, III in $40 \%$, and IV in $35 \%$, with no difference between the two groups. Extranodal disease was present in $8 \%$ of patients, with a relatively higher ratio of patients in the RT group. Nodular sclerosis was the most common histologic subtype of HD, with no difference between the two groups. Sixty-eight percent of patients in the RT group had B symptoms, versus $32 \%$ in the non-RT group. Fifty-three percent of patients had high ESR in the RT group compared to $47 \%$ in the non-RT group. Bulky disease was present in $65 \%$ of patients in the RT group, versus 53\% in the non-RT group. The number of patients who had metabolic CR and received RT was 68 (60\%), compared to 41 (52\%) of patients who did not receive RT, with no significant difference. Tumor size was less than $2 \mathrm{~cm}$ in eleven patients (three in the RT group and eight in the non-RT group), 2 to $5 \mathrm{~cm}$ in 78 patients (of whom 50 patients received radiotherapy), and more than $5 \mathrm{~cm}$ in 20 patients (of whom 15 received radiotherapy). Regarding the RT techniques, 84 patients received involved-field RT (IFRT) and 29 patients received involved-site RT.

\section{Survival analysis}

A total of 32 relapses occurred, constituting a 17\% incidence rate. Thirteen (12\%) relapses occurred in the RT group and $19(24 \%)$ relapses occurred in the non-RT group. Four relapses occurred in the involved-site RT group (14\%), compared to nine relapses in the IFRT group (11\%), with no difference
Table I Patient characteristics

\begin{tabular}{|c|c|c|c|c|}
\hline \multirow{2}{*}{$\begin{array}{l}\text { Prognostic } \\
\text { factors }\end{array}$} & \multirow{2}{*}{$\begin{array}{l}\text { All } \\
\text { patients, } \\
\text { n (\%) }\end{array}$} & \multicolumn{2}{|l|}{ RT group } & \multirow[t]{2}{*}{ Difference } \\
\hline & & $\begin{array}{l}\text { RT group, } \\
\text { n (\%) }\end{array}$ & $\begin{array}{l}\text { Non-RT } \\
\text { group, } \\
\text { n (\%) }\end{array}$ & \\
\hline Patients & $192(100)$ & $113(59)$ & $79(4 I)$ & \\
\hline \multicolumn{5}{|l|}{ Sex } \\
\hline Male & $117(61)$ & $78(69)$ & $39(49)$ & $\mathrm{S}$ \\
\hline Female & $75(39)$ & $35(31)$ & $40(5 I)$ & \\
\hline \multicolumn{5}{|l|}{ Pathological type } \\
\hline lymphocyte & $20(10.5)$ & II (10) & $9(11)$ & NS \\
\hline predominance & $115(60)$ & $71(63)$ & $44(56)$ & \\
\hline nodular sclerosis & $37(19)$ & $24(2 \mathrm{I})$ & $13(16.5)$ & \\
\hline mixed cellularity & $20(10.5)$ & $7(6)$ & $13(16.5)$ & \\
\hline \multicolumn{5}{|c|}{ lymphocyte } \\
\hline \multicolumn{5}{|l|}{ depleted } \\
\hline \multicolumn{5}{|l|}{ Stage } \\
\hline IIB & $48(25)$ & $31(28)$ & $17(2 \mid .5)$ & NS \\
\hline III & $76(40)$ & $40(35)$ & $36(45.5)$ & \\
\hline IV & $68(35)$ & $42(37)$ & $26(33)$ & \\
\hline \multicolumn{5}{|l|}{ B symptoms } \\
\hline Yes & $13 \mid(68)$ & $84(74)$ & 47 (59) & $\mathrm{S}$ \\
\hline No & $61(32)$ & $29(26)$ & $32(4 I)$ & \\
\hline \multicolumn{5}{|l|}{ Bulky disease } \\
\hline Yes & $115(60)$ & $73(65)$ & $42(53)$ & $\mathrm{S}$ \\
\hline No & $77(40)$ & $40(35)$ & 37 (47) & \\
\hline \multicolumn{5}{|c|}{ Extranodal disease } \\
\hline Yes & $15(8)$ & $10(9)$ & $5(6)$ & NS \\
\hline No & $177(92)$ & $103(91)$ & $74(94)$ & \\
\hline \multicolumn{5}{|l|}{ ESR } \\
\hline High & $101(53)$ & $63(56)$ & $38(48)$ & NS \\
\hline Normal & $91(47)$ & $50(44)$ & $4 I(52)$ & \\
\hline \multicolumn{5}{|c|}{ Radiotherapy technique } \\
\hline IFRT & & 84 & & $S$ \\
\hline INRT & & 29 & & \\
\hline \multicolumn{5}{|l|}{ Response } \\
\hline CR & $83(43)$ & $45(40)$ & $38(48)$ & NS \\
\hline PR (PET-negative) & $109(57)$ & $68(60)$ & $4 \mid(52)$ & \\
\hline \multicolumn{5}{|c|}{ Size of residual disease postchemotherapy } \\
\hline$\leq 2 \mathrm{~cm}$ & 11 & 3 & 8 & $\mathrm{~S}$ \\
\hline $2-5 \mathrm{~cm}$ & 78 & 50 & 28 & \\
\hline$\geq 5 \mathrm{~cm}$ & 20 & 15 & 5 & \\
\hline \multicolumn{5}{|l|}{ Disease status } \\
\hline Relapse & $32(17)$ & $13(12)$ & $19(24)$ & $S$ \\
\hline Free & $160(83)$ & $100(88)$ & $60(76)$ & \\
\hline \multicolumn{5}{|l|}{ Survival status } \\
\hline Dead & $20(10)$ & $9(8)$ & II (14) & NS \\
\hline Alive & $172(90)$ & $104(92)$ & $68(86)$ & \\
\hline 2nd malignancy & $5(3)$ & $3(3)$ & $2(2.5)$ & NS \\
\hline $\begin{array}{l}\text { Age (years), } \\
\text { mean } \pm S D\end{array}$ & $33 \pm 10$ & $39.5 \pm 12$ & $28 \pm 9$ & $S$ \\
\hline$\underline{\mathrm{RT}}$ range (Gy) & - & $20-36$ & - & \\
\hline$($ mean $\pm S D)$ & & $(28 \pm I I)$ & & \\
\hline
\end{tabular}

Abbreviations: CR, complete remission; ESR, erythrocyte sedimentation rate; IFRT, involved-field RT; INRT, involved nodal-field RT; NS, not significant; PET, positron emission tomography; PR, partial response; RT, radiotherapy; S, significant; $\mathrm{SD}$, standard deviation.

between the two groups $(P \leq 0.07)$. Twenty-five relapses out of 32 occurred in-fields or at the site of initial bulky disease or residual disease. Seven patients out of $113(6 \%)$ who received RT developed in-field relapse, compared to 18 patients out 
of $79(23 \%)$ in the non-RT group of patients. Distant relapse as initial site of recurrence occurred in only seven out of the 32 relapse patients $(22 \%)$. Most distant relapses happened in the RT group (six out of every seven patients), and only one patient developed distant relapse in the non-RT group of patients.

Twenty patients died during the period of analysis: nine patients (8\%) in the RT group and eleven patients (14\%) in the non-RT group. The documented second malignancies (however it was early) were observed in only five patients: three patients in the RT group compared to two in the non-RT group. Four of these five patients had thyroid malignancy, and the other one developed breast cancer. The breast cancer incident was reported in the non-RT group.

At 5 years, DFS was $79 \% \pm$ SD $9 \%$ and OS was $85 \% \pm 9 \%$ (Table 2, Figure 1). The difference between the RT group and the non-RT group was statistically significant regarding 5-year DFS: $86 \% \pm 7 \%$ and $74 \% \pm 9 \%$, respectively, with $P \leq 0.02$. On the other hand, the 5 -year OS was $90 \% \pm 5 \%$ for the RT group and $83 \% \pm 8 \%$ for the non-RT group, with no statistical difference $(P \leq 0.3)$ (Figure 2$)$.

The number of relapses correlated to initial bulky and residual PET-negative disease is shown in Table 3. It was found that the worst affected patients were those with initial bulky disease and metabolic CR; however, no statistical significance was noted due to the unequal distribution of cases.

\section{Discussion}

The conflicting results of consolidation RT after chemotherapy in advanced-stage HD has made its role debatable. Retrospective studies have demonstrated that adding low-dose RT to all initial disease sites after CR decreases the relapse rate by $25 \%$ and significantly improves OS. ${ }^{4}$ Also, a Southwest Oncology Group (SWOG) randomized trial of 278 patients with stage III or IV HD has proved that the addition of low-dose RT to all sites of initial disease after a complete response to MOPP/ABV chemotherapy (involving mechlorethamine, Oncovin (vincristine), procarbazine, prednisone, Adriamycin, and bleomycin) improves remission duration in patients with advanced-stage HD. ${ }^{5}$

Another important randomized trial questioning the role of consolidation RT after CR following six cycles of ABVD

Table 2 Survival status

\begin{tabular}{lllll}
\hline Survival & All & \multicolumn{2}{l}{ RT group } & P-value \\
\cline { 3 - 4 } & patients & $\begin{array}{l}\text { RT } \\
\text { group }\end{array}$ & $\begin{array}{l}\text { Non-RT } \\
\text { group }\end{array}$ & \\
\hline 5-year disease-free survival & $79 \% \pm 9 \%$ & $86 \% \pm 7 \%$ & $74 \% \pm 9 \%$ & $\leq 0.02$ \\
5-year overall survival & $85 \% \pm 9 \%$ & $90 \% \pm 5 \%$ & $83 \% \pm 8 \%$ & $\leq 0.3$ \\
\hline
\end{tabular}

Abbreviation: RT, radiotherapy.
Table 3 Distribution of relapses among patients according to bulky disease presentation and response following chemotherapy

\begin{tabular}{lll}
\hline Patient criteria & $\begin{array}{l}\text { Number } \\
\text { of patients }\end{array}$ & $\begin{array}{l}\text { Number of } \\
\text { relapses (\%) }\end{array}$ \\
\hline $\begin{array}{l}\text { Initial bulky disease with } \\
\text { radiological CR and metabolic CR }\end{array}$ & 83 & $13(16)$ \\
$\begin{array}{l}\text { Initial bulky disease with } \\
\text { radiological PR/metabolic CR }\end{array}$ & 32 & $12(37)$ \\
$\begin{array}{l}\text { Initial non-bulky disease with } \\
\text { radiological PR/metabolic CR }\end{array}$ & 77 & $7(9)$ \\
\hline
\end{tabular}

Abbreviations: $C R$, complete remission; PR, partial response.

was performed at Tata Medical Center, Kolkata, India. ${ }^{6}$ Fifty percent of the patients in this study had stage III or IV HD. A subgroup analysis of the advanced-stage patients showed a statistically significant improvement of both 8-year eventfree survival (EFS) and 8-year OS with added RT compared with ABVD alone (EFS 78\% versus 59\%; $P \leq 0.03$ and $\mathrm{OS}$ $100 \%$ versus $80 \% ; P \leq 0.006$ ).

Omitting RT Stanford V has shown inferior results for cases with disease larger than $5 \mathrm{~cm}$ disease. ${ }^{7,8}$ Recent metaanalysis of several randomized studies has demonstrated that the addition of RT to chemotherapy reduces the rate of relapse, without any survival benefit of a combined modality compared to chemotherapy alone. ${ }^{9}$

On the other hand, Aleman et al reported the results of a randomized study that evaluated the role of IFRT in patients with stage III/IV HD who obtained CR after MOPP/ABV. Patients received six or eight cycles of MOPP/ABV; patients achieved $\mathrm{CR}$ were randomized between observation (161 patients) and RT (172 patients). The authors concluded that IFRT does not improve DFS and leads to inferior 5-year OS rates $(P \leq 0.07)$. This study also reported a higher rate of second malignancies in the RT arm. ${ }^{2}$ However, it is of interest to note that the second malignancy risk in HD long-term survivors is not related to radiotherapy alone, as per Dores et al. ${ }^{10}$ Dores et al reported second malignancy relative risks of 2.3 (95\% confidence interval [CI]: 2.1-2.4) with RT, 1.7 (95\% CI: 1.5-1.9) with chemotherapy alone, and 3.1 (95\% CI: 2.6-3.6) with combined-modality therapy. Most studies have shown DFS benefit from IFRT without OS benefit. It has been argued that improvement of DFS with RT is of less value, because of the possibility of salvage of HD patients by high-dose chemotherapy and autologous bone marrow transplantation. ${ }^{11,12}$ Besides that, the idea of using PET imaging negativity as a basis for omitting radiotherapy after chemotherapy seems not to be a solid enough reason after the recently published article by Raemaekers et al, who reported higher relapse events in radiological $\mathrm{CR} / \mathrm{PR}$ and metabolic CR patients who received chemotherapy alone, 


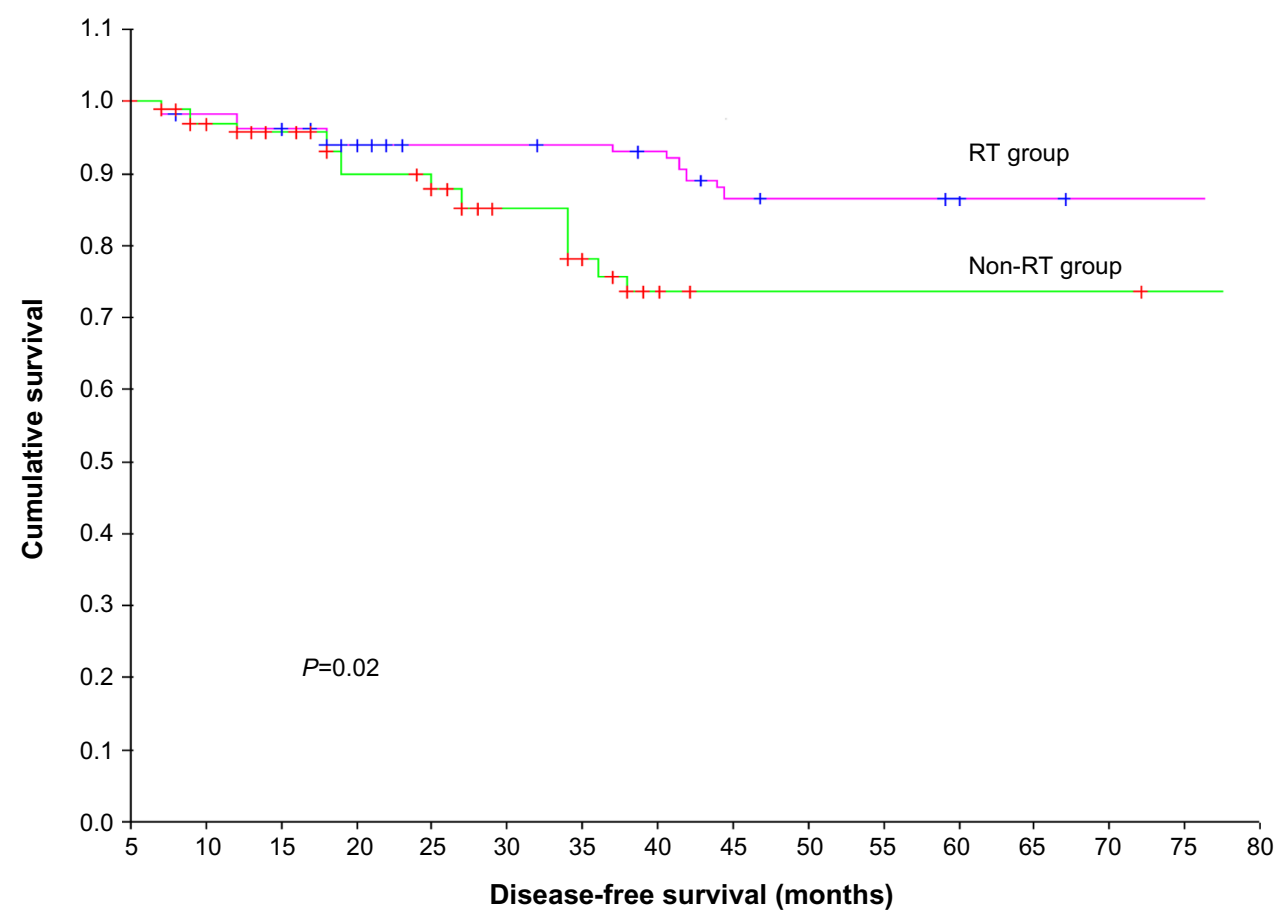

Figure I Disease-free survival.

Abbreviation: $\mathrm{RT}$, radiotherapy.

compared to patients who received IFRT post-chemotherapy in stage I and II HD. ${ }^{13}$ Recently, the UKLG LY09 randomized controlled trial has also shown that patients who received consolidation RT apparently had consistently better outcomes across all prognostic groups, which persisted in multivariate analysis. ${ }^{14}$ In our study, patients in the RT group had worse clinicopathological prognostic factors than the patients in the non-RT group; however, there was a tendency not to give RT to young females due to fears about second malignancy, especially breast cancer. With the advent of novel RT techniques and changing philosophies, the percentage of second malignancy in our patients was $3 \%$, which is lower than in the RT group in the study by Aleman et al (9\%), and an 8 -year risk of $12 \% .^{2}$

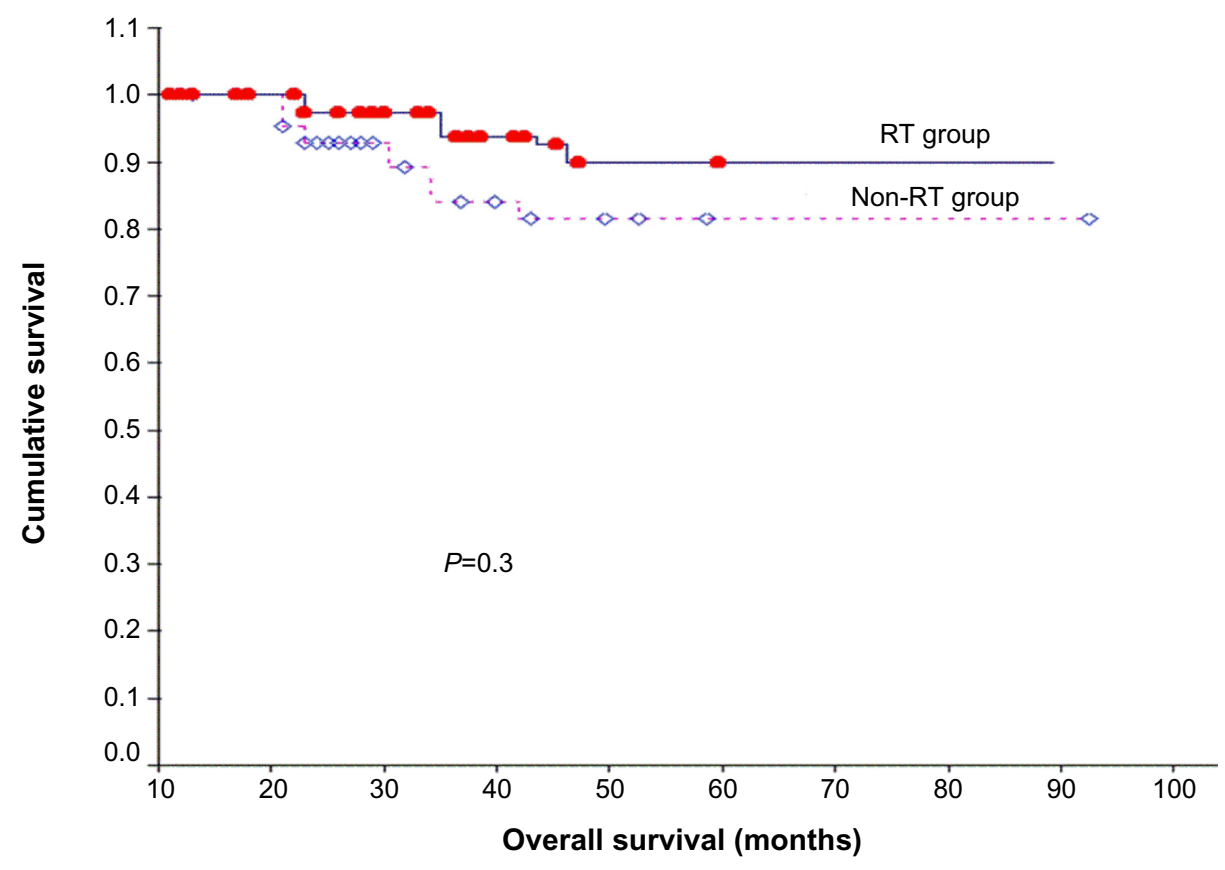

Figure 2 Overall survival. 
We were able to observe a statistically significant difference in 5-year DFS rates between the RT group ( $865 \pm 7 \%)$ and the non-RT group ( $74 \% \pm 9 \%)$. These results were better than those reported by Laskar et al, who showed DFS rates of $78 \%$ and $59 \%$ in the RT group and non-RT group, respectively. ${ }^{6}$

Our OS data are comparable to those of a retrospective study by Viani et al, ${ }^{15}$ who reported OS rates of $91.3 \%$ in patients in the RT group and $72.6 \%$ of patients in the non-RT group with a significant $P$-value.

Further, improvement in DFS with RT in our study is consistent with the findings of the German Society for Paediatric Oncology and Haematology (GPOH), who assessed the impact of omitting RT on DFS and OS for all patients achieving CR. ${ }^{16}$ Overall, EFS was $92 \%$ for patients receiving RT and $88 \%$ for those receiving no radiation $(P=0.05)$. The benefit of RT on DFS was greater in patients with advanced-stage disease at presentation. Our findings are also consistent with those of the Groupe d'Etude des Lymphomes de l'Adulte (GELA), who compared two extra cycles of ABVD versus consolidation radiotherapy after the standard six cycles of $A B V D$ and showed poor outcomes of patients who did not receive RT. ${ }^{17}$

\section{Conclusion}

Our results, though retrospective, show the importance of consolidation RT in patients with radiological CR or PR with metabolic CR and initially bulky HD regarding DFS improvement; however, no additional benefit to OS was found. Further similar, large, randomized trials are warranted to identify groups of advanced-stage HD patients who would benefit from RT.

\section{Disclosure}

The authors report no conflicts of interest in this work.

\section{References}

1. Diehl V, Franklin J, Hasenclever D, et al. BEACOPP, a new doseescalated and accelerated regimen, is at least as effective as COPP/ ABVD in patients with advanced-stage Hodgkin's lymphoma: interim report from a trial of the German Hodgkin's Lymphoma Study Group. J Clin Oncol. 1998;16:3810-3821.

2. Aleman BM, Raemaekers JM, Tirelli U, et al; European Organization for Research and Treatment of Cancer Lymphoma Group. Involved-field radiotherapy for advanced Hodgkin's lymphoma. $N$ Engl J Med. 2003;348:2396-2406.

Journal of Blood Medicine

\section{Publish your work in this journal}

The Journal of Blood Medicine is an international, peer-reviewed, open access, online journal publishing laboratory, experimental and clinical aspects of all topics pertaining to blood based medicine including but not limited to: Transfusion Medicine; Blood collection, Donor issues, Transmittable diseases, and Blood banking logistics; Immunohematology; Artificial and alternative
3. Cheson BD, Pfistner B, Juweid ME, et al; International Harmonization Project on Lymphoma. Revised response criteria for malignant lymphoma. J Clin Oncol. 2007;25(5):579-586.

4. Prosnitz LR, Wu JJ, Yahalom J. The case for adjuvant radiation therapy in advanced Hodgkin's disease. Cancer Invest. 1996;14:361-370.

5. Fabian CJ, Mansfield CM, Dahlberg S, et al. Low-dose involved field radiation after chemotherapy in advanced Hodgkin's disease. A Southwest Oncology Group randomized study. Ann Intern Med. 1994;120:903-912.

6. Laskar S, Gupta T, Vimal S, et al. Consolidation radiation after complete remission in Hodgkin's disease following six cycles of doxorubicin, bleomycin, vinblastine, and dacarbazine chemotherapy: is there a need? J Clin Oncol. 2004;22:62-68.

7. Horning SJ, Hoppe RT, Breslin S, Bartlett NL, Brown BW, Rosenberg SA. Stanford V and radiotherapy for locally extensive and advanced Hodgkin's disease: mature results of a prospective clinical trial. J Clin Oncol. 2002;20:630-637.

8. Chisesi T, Federico M, Levis A, et al; Intergruppo Italiano Linfomi. ABVD versus stanford V versus MEC in unfavourable Hodgkin's lymphoma: results of a randomised trial. Ann Oncol. 2002;13 Suppl 1:102-106.

9. Loeffler M, Brosteanu O, Hasenclever D, et al. Meta-analysis of chemotherapy versus combined modality treatment trials in Hodgkin's disease. International Database on Hodgkin's Disease Overview Study Group. J Clin Oncol. 1998;16:818-829.

10. Dores GM, Metayer C, Curtis RE, et al. Second malignant neoplasms among long-term survivors of Hodgkin's disease: a population-based evaluation over 25 years. J Clin Oncol. 2002;20:3484-3494.

11. Federico M, Bellei M, Brice P, et al; EBMT/GISL/ANZLG/SFGM/ GELA Intergroup HD01 Trial. High-dose therapy and autologous stem-cell transplantation versus conventional therapy for patients with advanced Hodgkin's lymphoma responding to front-line therapy. J Clin Oncol. 2003;21:2320-2325.

12. Sureda A, Arranz R, Iriondo A, et al; Grupo Español de Linformas/ Transplante Autólogo de Médula Osea Spanish Cooperative Group. Autologous stem-cell transplantation for Hodgkin's disease: results and prognostic factors in 494 patients from the Grupo Español de Linfomas/ Transplante Autólogo de Médula Osea Spanish Cooperative Group. J Clin Oncol. 2001;19:1395-1404.

13. Raemaekers JM, André MP, Federico M, et al. Omitting radiotherapy in early positron emission tomography-negative stage I/II Hodgkin lymphoma is associated with an increased risk of early relapse: clinical results of the preplanned interim analysis of the randomized EORTC/ LYSA/FIL H10 trial. J Clin Oncol. 2014;32(12):1188-1194.

14. Johnson PW, Sydes MR, Hancock BW, Cullen M, Radford JA, Stenning SP. Consolidation radiotherapy in patients with advanced Hodgkin's lymphoma: survival data from the UKLG LY09 randomized controlled trial (ISRCTN97144519). J Clin Oncol. 2010;28(20):3352-3359.

15. Viani GA, Castilho MS, Novaes PE, et al. Chemotherapy followed by low dose radiotherapy in childhood Hodgkin's disease: retrospective analysis of results and prognostic factors. Radiat Oncol. 2006;1:38.

16. Rühl U, Albrecht M, Dieckmann K. Response-adapted radiotherapy in the treatment of pediatric Hodgkin's disease: an interim report at 5 years of the German GPOH-HD 95 trial. Int J Radiat Oncol Biol Phys. 2001;51:1209-1218.

17. Ferme C, Mounier N, Diviné M; Groupe d'Etudes des Lymphomes de l'Adulte. Current clinical trials for the treatment of adult advancedstage Hodgkin's disease: GELA experiences. Groupe d'Etudes des Lymphomes de l'Adulte. Ann Oncol. 2002;13 Suppl 1:96-97.

\section{Dovepress}

blood based therapeutics; Hematology; Biotechnology/nanotechnology of blood related medicine; Legal aspects of blood medicine; Historical perspectives. The manuscript management system is completely online and includes a very quick and fair peer-review system. Visit http://www.dovepress.com/ testimonials.php to read real quotes from published authors. 